\title{
Development, characterization, sintering, dielectric and optical properties of $\mathrm{NdBa}_{2} \mathrm{ZrO}_{5.5}$ nanocrystals
}

\author{
V RATHEESH KUMAR, P R S WARIAR* , R PAZHANI ${ }^{\dagger}$, J K THOMAS ${ }^{\dagger}$, R JOSE $^{\S}$ and J KOSHY \\ Department of Physics, University College, Trivandrum 695 034, India \\ $\dagger$ Department of Physics, Mar Ivanios College, Trivandrum 695 015, India \\ $\S$ University of Malaysia Pahang, 26300 Kuantan, Malaysia
}

MS received 3 September 2010; revised 5 August 2011

\begin{abstract}
Nanocrystalline $\mathrm{NdBa}_{2} \mathrm{ZrO}_{5.5}$ has been successfully synthesized through a single step auto-ignition combustion route for the first time. X-ray diffraction and Fourier transform infrared spectroscopy revealed that the combustion product is phase pure and has an ordered cubic perovskite structure. The phase transitions and thermal stability of the nanopowder were investigated by differential thermal and thermogravimetric analyses. Transmission electron microscopy results indicated that the particle sizes are $20-30 \mathrm{~nm}$. Selected area electron diffraction pattern has shown that as-prepared powder is polycrystalline in nature. The optical absorption spectra analysis confirmed that the material falls to the semiconducting range with a bandgap of $\sim 3.69 \mathrm{eV}$ and therefore, could be used as transparent wide bandgap semiconductor. The relative density of the sintered sample is $\sim 96 \%$ at $1510{ }^{\circ} \mathrm{C} \mathrm{for} 2 \mathrm{~h}$. The surface morphology of the sintered pellet has been studied by scanning electron microscopy and the average grain size observed is $\sim 0.7 \mu \mathrm{m}$. Dielectric constant $\left(\varepsilon_{\mathrm{r}}\right)$ of $\mathrm{NdBa}_{2} \mathrm{ZrO}_{5.5}$ at $5 \mathrm{MHz}$ is 29.6 and loss factor $(\tan \delta)$ is $4 \times 10^{-2}$ at room temperature.
\end{abstract}

Keywords. Perovskites; nanoparticles; combustion synthesis; dielectric properties; energy bandgap.

\section{Introduction}

Materials with perovskite-type structure are attracting intense interest in many applied and fundamental areas of solid-state science and advanced materials research. This is because of a broad range of physical and chemical properties (Kimura and Tokura 2000; Lichtenburg et al 2001) of these types of materials. Perovskites have a general stoichiometry, $\mathrm{ABO}_{3}$ and are formed by a network of corner sharing $\mathrm{BO}_{6}$ octahedra, in which all oxygen atoms are in twocoordinate, bridging positions between adjacent $B$ sites; the dodecahedral interstices of the oxygen sub-lattice is occupied by a second cation $A$. Perovskites exist in different crystal structures due to the feasibility of substituting, either partially or fully, alkaline earth, rare earth and transition metal ions in the $A$ and $B$ sites of perovskite unit cell. The substitution results in an arrangement of the cations either orderly or randomly in $A$ and $B$ sites of the basic perovskite unit cell, thereby, forming a complex perovskite structure. Transition metals, which usually occupy the $B$-sublattice of the perovskite-type structure, have their frontier $d$-orbitals close in energy to the $\mathrm{O}(2 p)$ orbitals. The electronic structure of the perovskite-type oxides near the Fermi level is, therefore, dominated by the hybridization of these orbitals (Goodenough 1971). The top of the valence band is predominantly formed by the $\mathrm{O}(2 p)$ orbitals, whereas bottom

\footnotetext{
*Author for correspondence (prswarriar@yahoo.com)
}

of the conduction band consists mainly of $d$-orbitals of the transition metal. The bandgap energy is one of the important properties of functional materials for photochemical applications (Osterloh 2008). In $d^{0}$ perovskite-type oxides, the bandgap energy is determined by the difference between energy of the $d$-orbitals of the transition metals and $\mathrm{O}(2 p)$ orbitals.

In view of their chemical stability, synthesis of $\mathrm{NdBa}_{2} \mathrm{ZrO}_{5.5}$, a complex perovskite oxide, has been investigated for possible applications as substrates for high $T_{\mathrm{C}}$ superconductors (HTS) and in these investigations, $\mathrm{NdBa}_{2} \mathrm{ZrO}_{5.5}$ was synthesized through solid state route (Tovar et al 2007). However, a single phase $\mathrm{NdBa}_{2} \mathrm{ZrO}_{5.5}$ could be obtained through solid state reaction route only after prolonged calcinations of the reaction mixture at $1000^{\circ} \mathrm{C}$ for $38 \mathrm{~h}$ with multiple intermediate grindings. Also we have not reported the sintering behaviour or dielectric properties of $\mathrm{NdBa}_{2} \mathrm{ZrO}_{5.5}$.

Synthesis of advanced ceramics as nanocrystals is one of the major fields in materials processing technology (Glieter 2000; Karagedov and Lyakhov 1999; Ravichandran et al 2004) and the advantages of nanocrystalline materials over microstructured materials are superior phase homogeneity, sinterability and microstructure leading to unique mechanical, electrical, dielectric, magnetic, optical and catalytic properties (Suryanarayana 1994; Skandan et al 1999). The coarse-grained powders synthesized using the conventional solid state route have disadvantages like larger particle size, high temperature processing and relatively lower phase 
purity. In this paper, we report the synthesis, characterization, sintering behaviour, optical and dielectric properties of single phase nanoparticles of $\mathrm{NdBa}_{2} \mathrm{ZrO}_{5.5}$, for the first time. The product was characterized by XRD, TGA/DTA, FT-IR, UV-VIS, TEM and SEM.

\section{Experimental}

The basic step for the synthesis of $\mathrm{NdBa}_{2} \mathrm{ZrO}_{5.5}$ nanoparticles was to prepare an aqueous solution containing $\mathrm{Ba}^{2+}$, $\mathrm{Nd}^{3+}$ and $\mathrm{Zr}^{4+}$ ions by dissolving stoichiometric amounts of high purity $\mathrm{Ba}\left(\mathrm{NO}_{3}\right)_{2}(99.9 \%, \mathrm{CDH}), \mathrm{Nd}_{2} \mathrm{O}_{3}(99.9 \%, \mathrm{CDH})$ and $\mathrm{ZrOCl}_{2} \cdot 8 \mathrm{H}_{2} \mathrm{O}$ (99.5\%, Sigma-Aldrich) in suitable solvents. $\mathrm{Nd}_{2} \mathrm{O}_{3}$ was dissolved in $0 \cdot 1 \mathrm{~N}$ nitric acid, $\mathrm{Ba}\left(\mathrm{NO}_{3}\right)_{2}$ and $\mathrm{ZrOCl}_{2} \cdot 8 \mathrm{H}_{2} \mathrm{O}$ in double distilled water. The solutions were mixed together in a glass beaker and sufficient amount of citric acid $(99 \%, \mathrm{CDH})$ was added to the solution containing metal ions to get the precursor complex, maintaining the citric acid to cation ratio at unity. Subsequently, nitric acid and ammonium hydroxide were added to the system to adjust the oxidant/fuel ratio, where nitric acid acted as the oxidant and liquor ammonia acted as the fuel. The solution containing the complex precursor at neutral $\mathrm{pH}$ was then heated to about $250{ }^{\circ} \mathrm{C}$ on a hot plate. The solution boiled on heating and formed a syrupy liquid, which underwent dehydration and decomposition leading to smooth deflation producing foam. The foam then ignited by itself on persistent heating giving voluminous and fluffy product of combustion. The combustion product was subsequently characterized as single phase nanocrystals of $\mathrm{NdBa}_{2} \mathrm{ZrO}_{5.5}$.

The as-synthesized $\mathrm{NdBa}_{2} \mathrm{ZrO}_{5.5}$ nanoparticles were characterized for crystal phase identification by powder X-ray diffraction (XRD) technique using a X-ray Diffractometer (Model Bruker D-8) with nickel filtered $\mathrm{CuK} \alpha$ radiations $(\lambda=0.15406 \mathrm{~nm})$ in the range of $2 \theta$ between $20^{\circ}$ and $70^{\circ}$. The infrared spectra (IR) of the samples were recorded in the range $400-4000 \mathrm{~cm}^{-1}$ on a Thermo-Nicolet Avatar 370 Fourier Transform Infrared (FT-IR) Spectrometer. Samples were prepared by mixing dried $\mathrm{NdBa}_{2} \mathrm{ZrO}_{5.5}$ nanoparticles with $\mathrm{KBr}$ and pressing them into pellets. The thermal decomposition behaviour of the powder was studied by differential thermal analysis (DTA) and thermogravimetric analysis (TGA) using a simultaneous Perkin-Elmer TG/DTA thermal analyser in the range $40-1100{ }^{\circ} \mathrm{C}$ at a heating rate of $20^{\circ} \mathrm{C} / \mathrm{min}$ in nitrogen atmosphere. The optical absorption spectrum of the nanopowder at room temperature was obtained using a Cary 100 BIO UV-VIS Spectrophotometer in the wavelength range 190-900 $\mathrm{nm}$. The morphology of the nanocrystallites was inspected using a transmission electron microscope (TEM, JEOL 2010Fas) with an accelerating voltage of $200 \mathrm{kV}$. For TEM observation, the powder samples were dispersed in methanol and sonicated for $30 \mathrm{~min}$ to obtain better particle dispersion and allowing a drop of this to dry on a carbon-coated copper grid.

To study sinterability of the $\mathrm{NdBa}_{2} \mathrm{ZrO}_{5.5}$ nanoparticles obtained by the present combustion method, the combustion derived powders were mixed with $5 \%$ polyvinyl alcohol as binder and uniaxially pressed in the form of circular discs of $14 \mathrm{~mm}$ diameter and $\sim 2 \mathrm{~mm}$ thickness at a pressure of about $350 \mathrm{MPa}$ using a hydraulic press. The binder was removed by heating the pellet at $600{ }^{\circ} \mathrm{C}$ for $30 \mathrm{~min}$. The pellet was then sintered at $1510{ }^{\circ} \mathrm{C}$ for $2 \mathrm{~h}$ in a programmable furnace in air at a heating/cooling rate of $10{ }^{\circ} \mathrm{C} / \mathrm{min}$. The density of the sintered specimen was measured using Archimedes method with distilled water as the liquid medium. The microstructure of sintered samples after thermal etching was investigated by scanning electron microscope (JEOL, Model-JSM-6390LA, Analytical SEM).

The simplest way to measure the dielectric constant of a material is based on the measurement of capacitance of capacitor using the material, whose dielectric constant is to be measured, as the dielectric medium between a parallel plate or co-axial capacitor. The capacitance $(C)$ of a capacitor is related to dielectric constant $\varepsilon_{\mathrm{r}}$ as

$$
C=\frac{\varepsilon_{\mathrm{o}} \varepsilon_{\mathrm{r}} A}{d},
$$

where $A$ is the cross-sectional area of the capacitor, $d$ the thickness of the dielectric material and $\varepsilon_{\mathrm{o}}$ the permittivity of free space $\left(8.85 \times 10^{-12} \mathrm{~F} / \mathrm{m}\right)$. The capacitance and loss tangent measurements were carried out on the sample in the form of pellet of about $10.48 \mathrm{~mm}$ in diameter and $1.68 \mathrm{~mm}$ in thickness using an LCR meter (HIOKI 3532-50). For dielectric measurements, silver electrodes were attached on either sides of the sintered pellet and dried at $80{ }^{\circ} \mathrm{C}$ for $15 \mathrm{~min}$. The dielectric constant and loss factor were calculated as a function of frequency $(1 \mathrm{kHz}-5 \mathrm{MHz})$.

\section{Results and discussion}

\subsection{XRD analysis}

Figure 1 shows XRD pattern of as-prepared $\mathrm{NdBa}_{2} \mathrm{ZrO}_{5.5}$ powder obtained by the present combustion synthesis. All the peaks are indexed for a complex cubic $(\mathrm{Fm} 3 \mathrm{~m})$ perovskite structure and the lattice constant calculated from the XRD data is $a=8.408 \AA$ and it agrees very well with the reported XRD data in the JCPDS cards No. 47-0387. The crystallite size calculated from full width at half-maximum (FWHM) using Scherrer formula is

$$
D=\frac{k \lambda}{\beta \cos \theta},
$$

where $\lambda$ is the wavelength of the $\mathrm{X}$-ray, $\beta$ the full width at half maximum (FWHM) of a diffraction peak, $\theta$ the diffraction angle and $k$ the Scherrer's constant of the order of unity for usual crystal $(\sim 0.9)$. The average particle size obtained from the XRD data for (220) plane in figure 1 is $\sim 24 \mathrm{~nm}$. No diffraction peak that could be related to impurity or secondary phase was observed in the XRD pattern. This shows that by adopting combustion method, phase pure and well crystalline powders of perovskite materials can be prepared 
within a short duration without the need for a calcinations step. It may be noted that a single phase $\mathrm{NdBa}_{2} \mathrm{ZrO}_{5.5}$ can be obtained through a solid state reaction route only after prolonged calcinations of the reaction mixture at $1000{ }^{\circ} \mathrm{C}$ with multiple intermediate grindings. Thus combustion process has energy and cost saving advantages.

\subsection{FT-IR spectrum analysis}

Figure 2 shows FT-IR spectrum of a typical as-prepared $\mathrm{NdBa}_{2} \mathrm{ZrO}_{5.5}$ powder. The asymmetric stretching and bending modes of the $\mathrm{BO}_{6}$ octahedra, usually dominate the IR spectra of perovskite materials (Ratheesh et al 1997). Therefore, in the present case, the strong band from $400 \mathrm{~cm}^{-1}$ is involving the asymmetric bending mode, $v_{4}\left(T_{1 \mathrm{u}}\right)$ of the $\mathrm{ZrO}_{6}$

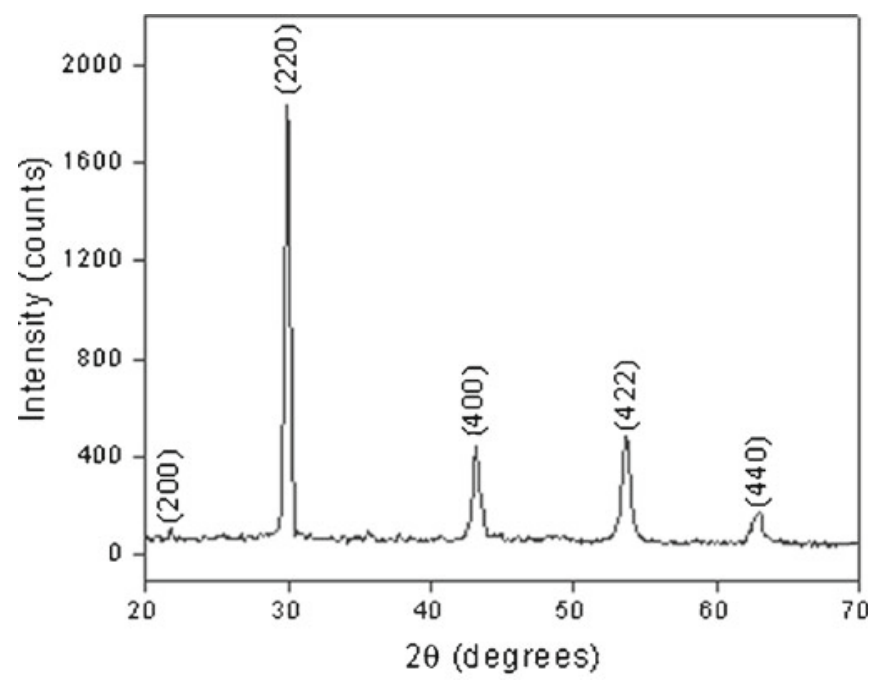

Figure 1. Powder XRD pattern of as-prepared $\mathrm{NdBa}_{2} \mathrm{ZrO}_{5.5}$ nanopowder.

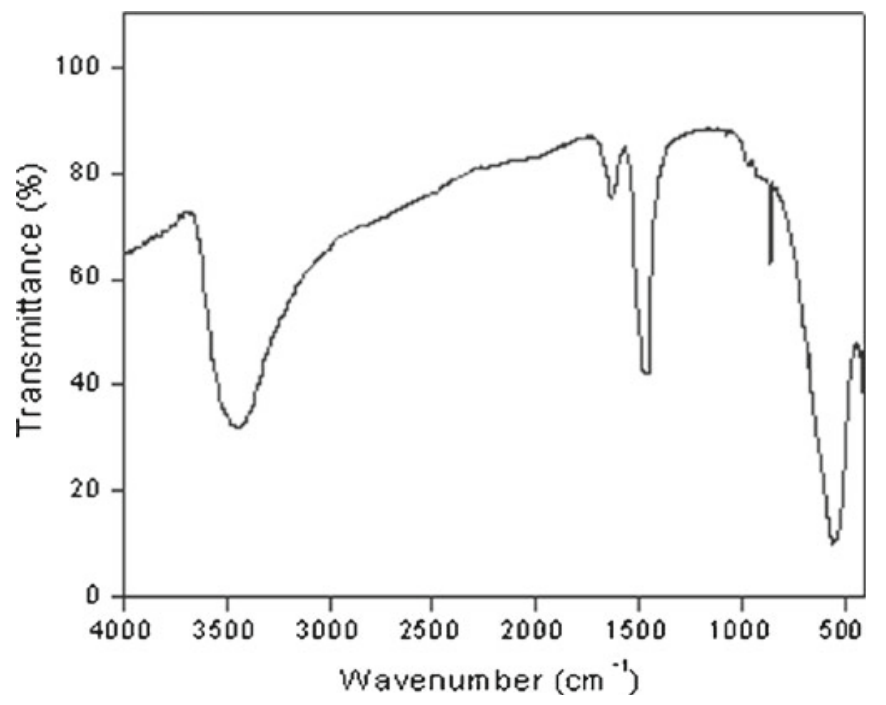

Figure 2. FT-IR spectrum of as-prepared $\mathrm{NdBa}_{2} \mathrm{ZrO}_{5.5}$ nanopowder. octahedra whilst the other strong broad band from $550 \mathrm{~cm}^{-1}$ can be assigned to the asymmetric stretching mode, $v_{3}\left(T_{1 \mathrm{u}}\right)$ of the $\mathrm{ZrO}_{6}$ octahedra. The same spectral pattern, with two strong and well defined IR bands in the 400-600 $\mathrm{cm}^{-1}$ region, has also been found in a great number of $\mathrm{A}_{2} \mathrm{BB}^{\prime} \mathrm{O}_{6}$ perovskite type materials and they were assigned in the same way (Corsmit et al 1972; Blasse and Corsmit 1973; Zheng et al 1998; Lavat et al 2001). Finally, the weak band from $864 \mathrm{~cm}^{-1}$ can be assigned to the originally IR inactive symmetric stretching mode, $v_{1}\left(A_{1 \mathrm{~g}}\right)$ of the $\mathrm{ZrO}_{6}$ octahedra, activated by symmetry lowering. The absorption bands around $1500-1700 \mathrm{~cm}^{-1}$ and $1300-1500 \mathrm{~cm}^{-1}$ are assigned to water bending vibration, and $\mathrm{CO}_{2}$ characteristic vibrations, respectively (Nyguist and Kagel 1971; Nakamoto 1986). The broad feature in the $3000-3600 \mathrm{~cm}^{-1}$ region is attributed to $\mathrm{O}-\mathrm{H}$ stretching of physisorbed water or from surfaceadsorbed hydroxyl groups. Thus, there was no evidence for the presence of any organic matter in the sample.

\subsection{Thermal analysis}

Figure 3 shows typical DTA and TGA curves of the asprepared powders of $\mathrm{NdBa}_{2} \mathrm{ZrO}_{5.5}$ up to $1100^{\circ} \mathrm{C}$. TGA curve shows a weight loss of $\sim 4 \%$ at about $100{ }^{\circ} \mathrm{C}$, which can be caused by the adsorbed moisture in the sample. The weight change corresponds to an endotherm on the DTA curve around $100{ }^{\circ} \mathrm{C}$. Thereafter, there is no substantial weight change or enthalpy change occurring in the sample at temperatures up to $1100{ }^{\circ} \mathrm{C}$, which implies that the combustion is complete and no organic matter is present in the sample. There is also no evidence of any phase transition taking place in the sample up to this temperature.

\subsection{TEM analysis}

TEM studies on the powder morphology of the as-prepared powder obtained by the combustion route showed that the

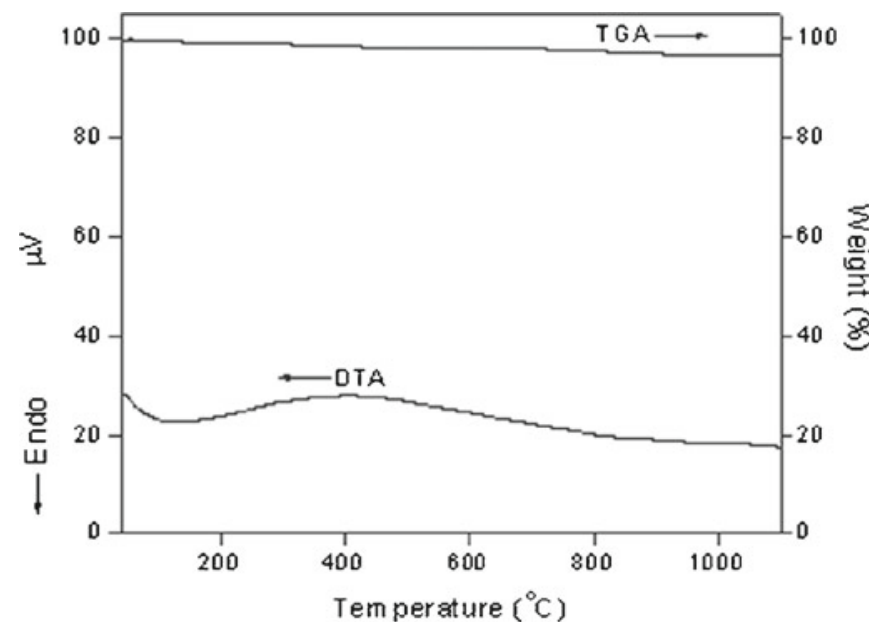

Figure 3. DTA/TGA curves of as-prepared $\mathrm{NdBa}_{2} \mathrm{ZrO}_{5.5}$ nanopowder. 

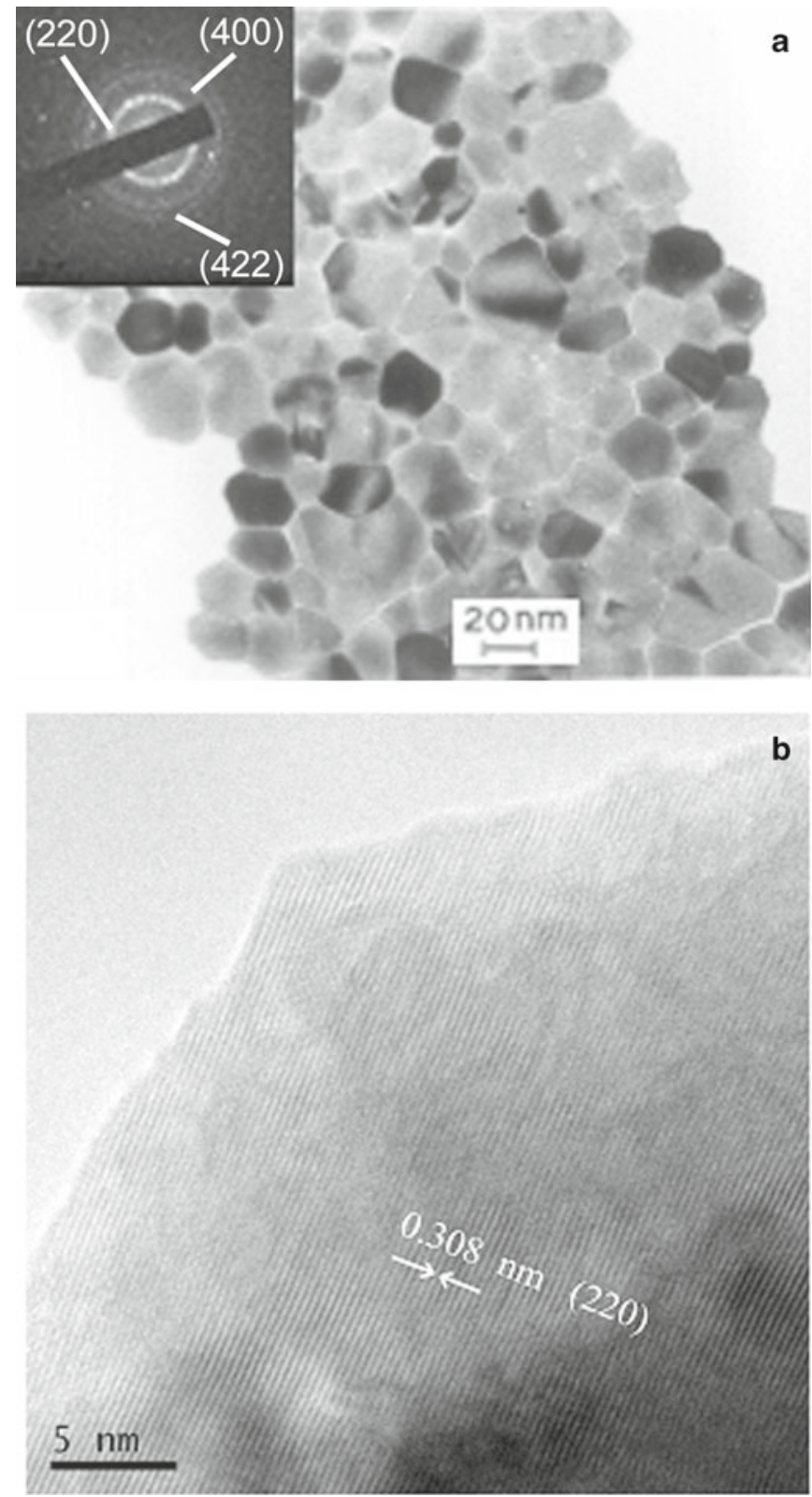

Figure 4. (a) TEM micrograph (inset shows corresponding SAED pattern) and (b) HRTEM lattice image of as-prepared $\mathrm{NdBa}_{2} \mathrm{ZrO}_{5.5}$ nanopowder.

Table 1. Lattice spacing for different crystal planes as measured from XRD and electron diffraction (ED) patterns of $\mathrm{Ba}_{2} \mathrm{NdZrO}_{5.5}$.

\begin{tabular}{ccc}
\hline$h k l$ & $d_{\mathrm{XRD}}(\AA)$ & $d_{\mathrm{ED}}(\AA)$ \\
\hline 220 & 3.028 & 3.080 \\
400 & 2.119 & 2.116 \\
422 & 1.729 & 1.722 \\
\hline
\end{tabular}

particles are of submicron size in the range $20-30 \mathrm{~nm}$ as shown in figure $4 \mathrm{a}$ and the inset shows the corresponding selected area electron diffraction (SAED) pattern. The ring

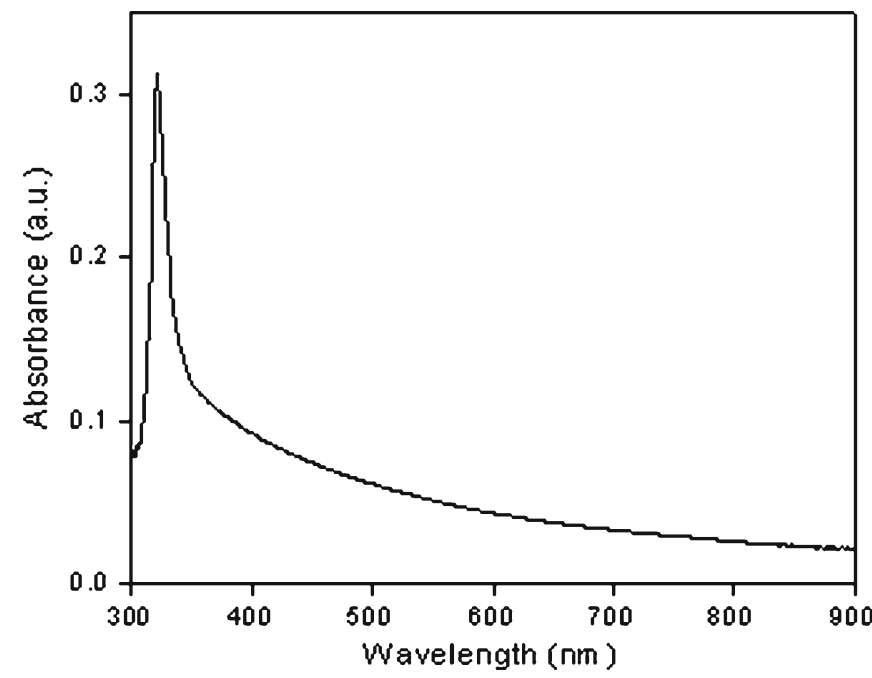

Figure 5. UV-absorption spectrum of nanocrystalline $\mathrm{NdBa}_{2} \mathrm{ZrO}_{5.5}$.

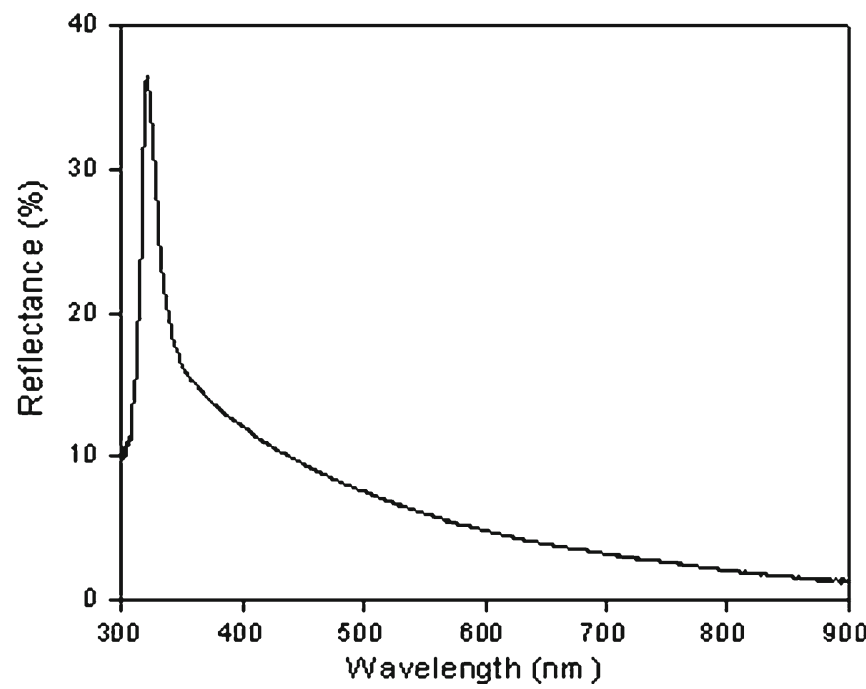

Figure 6. Variation of reflectance with wavelength for $\mathrm{NdBa}_{2} \mathrm{ZrO}_{5.5}$ nanopowder.

nature of the electron diffraction pattern is indicative of the polycrystalline nature of the crystallites, but the spotty nature of SAED can be due to the fact that the fine crystallites having related orientations are agglomerated together resulting in a limited set of orientations. The SAED pattern is indexed for a complex cubic perovskite structure and is in good agreement with the XRD data. Table 1 compares the lattice spacing $(d)$ calculated from XRD and SAED patterns. Figure $4 \mathrm{~b}$ is the high resolution lattice image (HRTEM) of the agglomerate sample which gives the crystal lattice stripe of the $\mathrm{Ba}_{2} \mathrm{NdZrO}_{5.5}$ particle. Indexing the lattice stripes, the typical lattice spacing corresponds to the interplanar spacing (d) of the (220) crystal plane which is $0.308 \mathrm{~nm}$. 


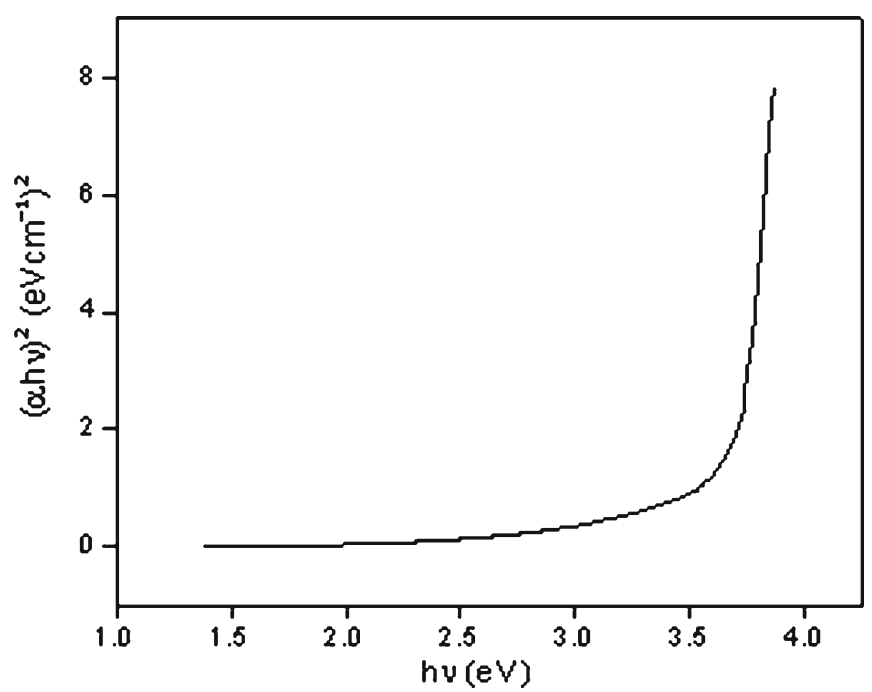

Figure 7. Energy bandgap determination of $\mathrm{NdBa}_{2} \mathrm{ZrO}_{5.5}$ nanocrystals from $(\alpha h v)^{2} v s h v$ graph.

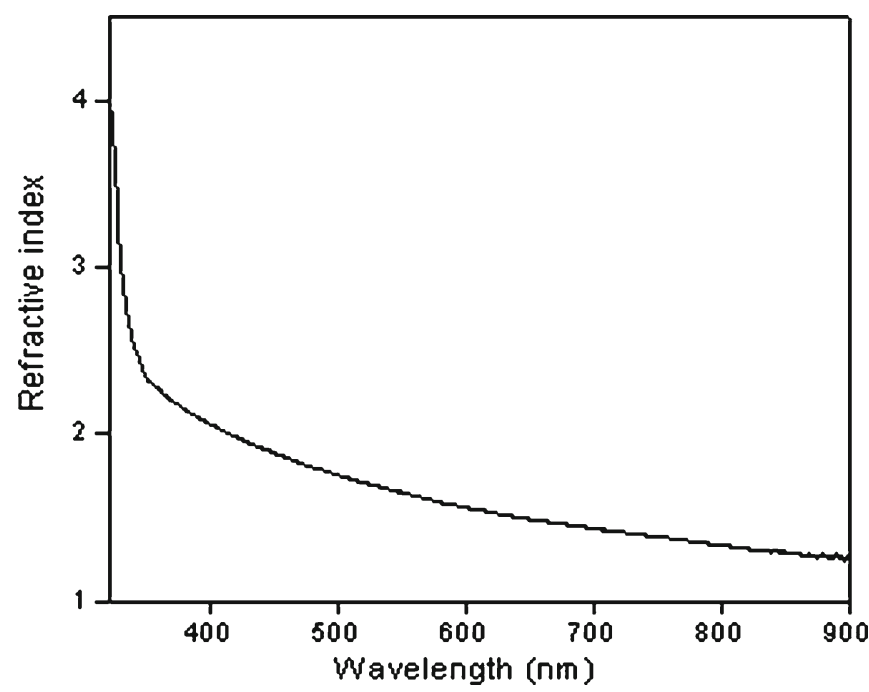

Figure 8. Variation of refractive index with wavelength for $\mathrm{NdBa}_{2} \mathrm{ZrO}_{5.5}$ nanopowder.

\subsection{Optical absorption studies}

The UV absorption and reflectance spectra of $\mathrm{NdBa}_{2} \mathrm{ZrO}_{5.5}$ nanoparticles dispersed in hydrogen peroxide (at room temperature) are shown in figures 5 and 6, respectively. From the spectrograph the absorption edge was found to occur at $\sim 336 \mathrm{~nm}$. The existence of sharp absorption edge is the characteristics of crystalline state of the material which corroborates the XRD analysis. It is observed from the figures that absorbance and reflectance show peaks in the ultra-violet region and decreases sharply with increasing wavelength and becomes almost constant towards the visible region. The property of very low absorbance and reflectance in the visible region makes the material a good candidate as transparent windows in solar cells.

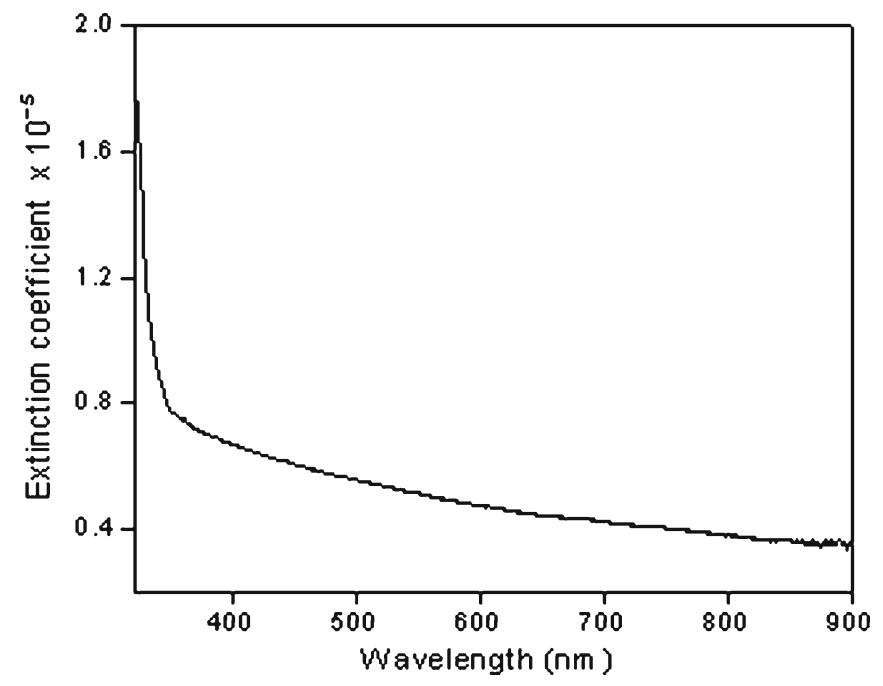

Figure 9. Variation of extinction coefficient with wavelength for nanocrystalline $\mathrm{NdBa}_{2} \mathrm{ZrO}_{5.5}$.

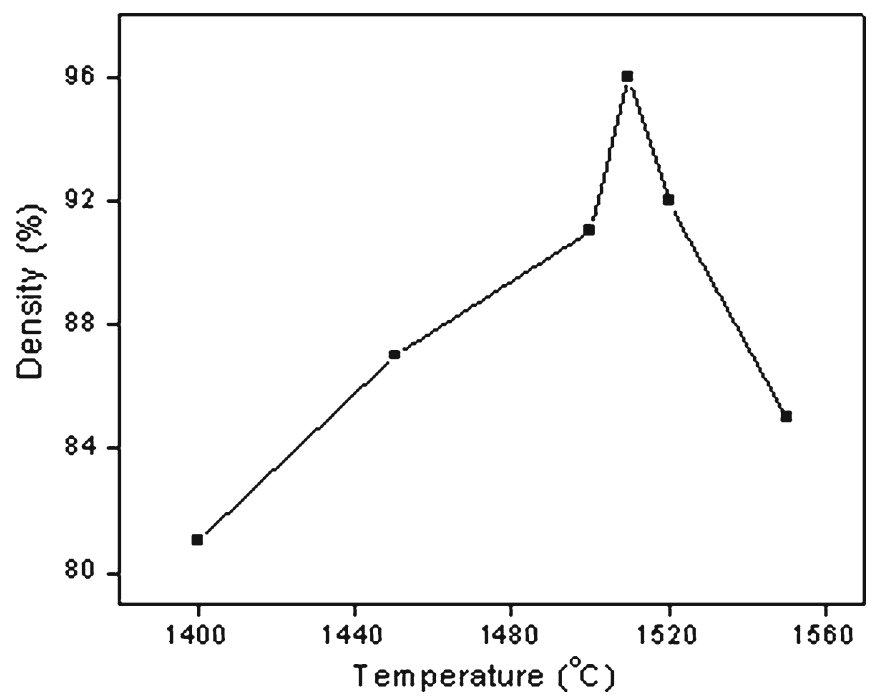

Figure 10. Variation of sintered density with temperature for $\mathrm{NdBa}_{2} \mathrm{ZrO}_{5.5}$ pellet.

According to Tauc relation, the absorption coefficient for direct band material is given by (Tauc 1974; Sharma et al 1992)

$$
\alpha h v=B\left(h v-E_{\mathrm{g}}\right)^{1 / 2},
$$

where $B$ is a constant, $\alpha$ the absorption coefficient, $h v$ the photon energy and $E_{\mathrm{g}}$ the bandgap. A graph between $(\alpha h v)^{2}$ $v s h v$ is plotted and shown in figure 7. The extrapolation of straight line to $(\alpha h v)^{2}=0$ axis gives value of the energy bandgap of the material which is found to be $\sim 3.69 \mathrm{eV}$. Since the bandgap of $\mathrm{NdBa}_{2} \mathrm{ZrO}_{5.5}$ lies in the $\mathrm{UV}$ region, the material finds applications in the field of heterogeneous photocatalysis for the aqueous photodecomposition of organic contaminants. Recently, we have reported the photocatalytic 
activities of complex perovskites under UV and solar light irradiations (Kumar et al 2011).

The variation of refractive index $(n)$ and extinction coefficient $(k)$ with wavelength of incident photon is shown in figures 8 and 9, respectively. Both $n$ and $k$ decrease exponentially with wavelength. The variations of $n$ and $k$ values in the investigated frequency range show that some interactions take place between photons and electrons. It is found that $n$ and $k$ show peaks around 4.0444 and $1.8217 \times 10^{-5}$ which is at the same photon energy, $3.8697 \mathrm{eV}$. Thus, at room temperature, nanocrystalline $\mathrm{NdBa}_{2} \mathrm{ZrO}_{5.5}$ falls to the semiconducting range with a bandgap of $\sim 3.69 \mathrm{eV}$ since the maximum value of refractive index $(n)$ occurred at energy ranges near where the maximum change in $k$ occurred (Greenway and Harbeke 1969). Therefore, the material could be used as transparent wide bandgap semiconductor.

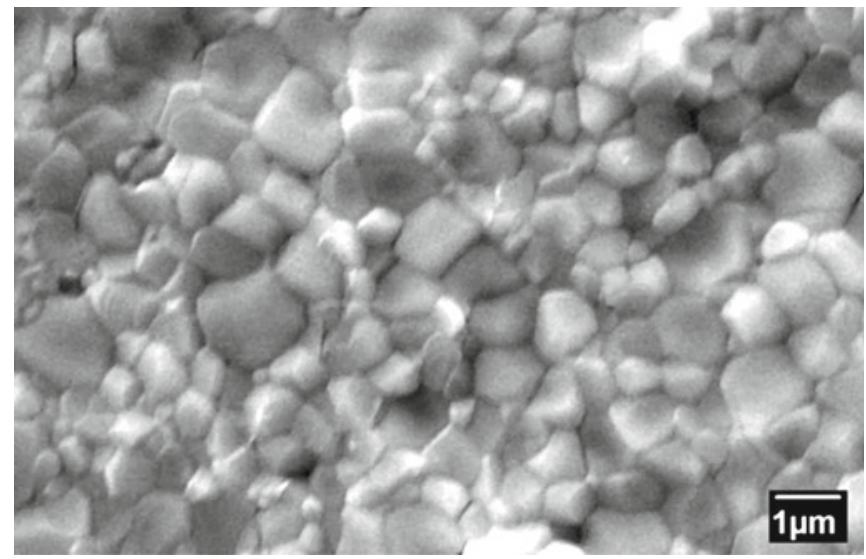

Figure 11. SEM secondary electron image of sintered pellet of $\mathrm{NdBa}_{2} \mathrm{ZrO}_{5.5}$.

\subsection{Sintering and dielectric studies}

The sintering behaviour of nanocrystals of $\mathrm{NdBa}_{2} \mathrm{ZrO}_{5.5}$ synthesized through the present combustion route was studied. The relative green density of the specimen used for the sintering study was $55 \pm 2 \%$ for a pressure of $350 \mathrm{MPa}$. Figure 10 indicates a strong correlation between bulk density of the pellet and sintering temperature for a soaking time of $2 \mathrm{~h}$. A sintered density of $\sim 96 \%$ of the theoretical value was obtained on sintering the compacted specimen at $1510{ }^{\circ} \mathrm{C}$ which seems to be very close to the optimum sintering temperature. Figure 11 shows SEM images of sintered specimen. No cracks or pores were observed on the surface. It is clear from the micrograph that densification was achieved without significant microstructural coarsening. The average grain size determined from SEM micrograph is $\sim 700 \mathrm{~nm}$.

The dielectric characteristics of $\mathrm{NdBa}_{2} \mathrm{ZrO}_{5.5}$ as a function of frequency measured at room temperature are shown in figure 12. Dielectric properties such as dielectric constant $\left(\varepsilon_{\mathrm{r}}\right)$ and loss factor $(\tan \delta)$ of the polycrystalline $\mathrm{NdBa}_{2} \mathrm{ZrO}_{5.5}$ was studied in the frequency range $1 \mathrm{kHz}$ to $5 \mathrm{MHz}$ at room temperature. The value of $\varepsilon_{\mathrm{r}}$ is high at low frequencies and decreases rapidly as frequency increases. This is due to the fact that at lower frequencies, dipoles are able to follow the frequency of applied field; as frequency increases dipoles are not able to follow the frequency of applied field. The dielectric relaxation results in high value of dielectric constant at low frequencies and low value of dielectric constant at higher frequencies. The behaviour of decrease of $\tan \delta$ with increase in frequency is consistent with that of the dielectric constant of the sample. The specimen showed a moderate dielectric constant $\left(\varepsilon_{\mathrm{r}}=29.6\right)$ and loss factor ( $\tan \delta=4 \times 10^{-2}$ ) at $5 \mathrm{MHz}$ frequencies at room temperature, which indicates that the material is suitable for microwave applications.

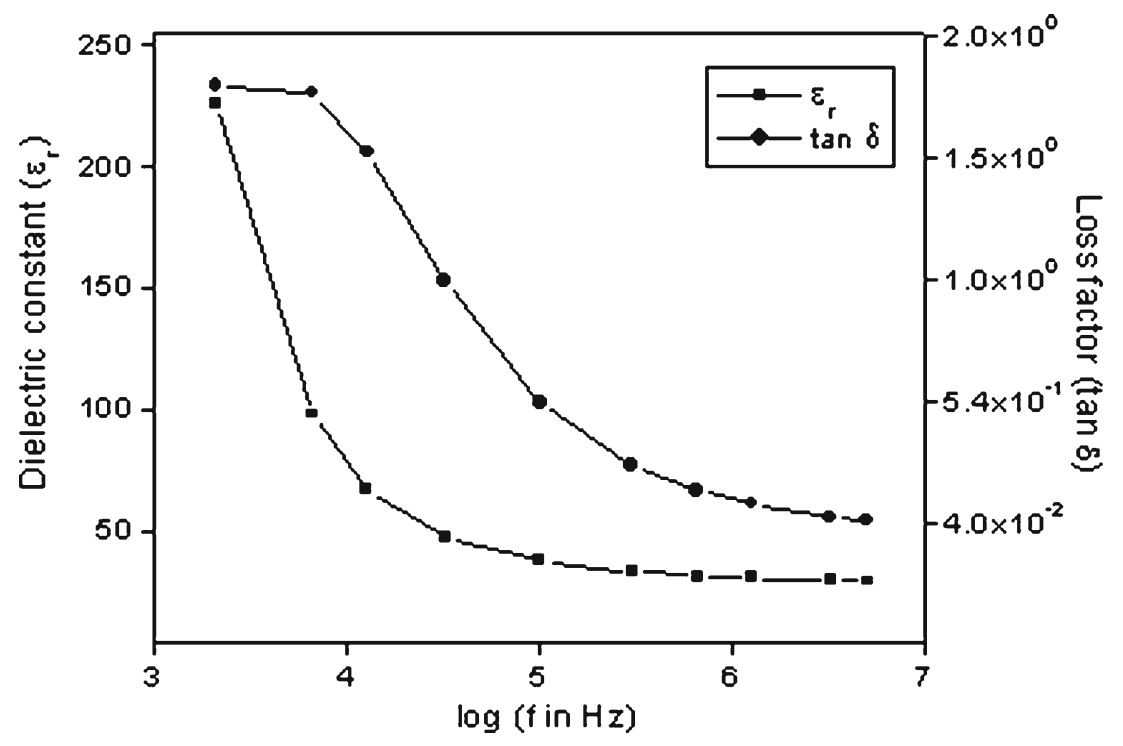

Figure 12. Variation of dielectric constant $\left(\varepsilon_{\mathrm{r}}\right)$ and loss factor $(\tan \delta)$ with frequency. 


\section{Conclusions}

The single step auto-ignition combustion technique was employed to synthesize nanocrystalline $\mathrm{NdBa}_{2} \mathrm{ZrO}_{5.5}$. X-ray diffraction studies have shown that the combustion product is phase pure $\mathrm{NdBa}_{2} \mathrm{ZrO}_{5.5}$ and has a complex cubic perovskite structure. There was no evidence for the presence of any organic matter in the sample as suggested by FT-IR analysis. TG/DTA studies revealed that no phase transition occurs in the as-prepared powder at high temperatures. TEM micrographs confirmed the nanoscale size (20-30 nm) of the particles. SAED image shows that the oxide material is polycrystalline in nature. The lattice planes in HRTEM image indicate that even the smallest particles are reasonably well crystallized. The UV-VIS spectrum analysis revealed that the material is a wide bandgap $\left(E_{\mathrm{g}}=3.69 \mathrm{eV}\right)$ semiconductor at room temperature. The nanocrystals of $\mathrm{NdBa}_{2} \mathrm{ZrO}_{5.5}$ could be sintered to $\sim 96 \%$ of the theoretical density at a temperature of $1510^{\circ} \mathrm{C}$ for $2 \mathrm{~h}$. SEM image of the sintered specimen indicates high densification of the material with an average grain size of $\sim 700 \mathrm{~nm}$. The room temperature dielectric constant $\left(\varepsilon_{\mathrm{r}}\right)$ and loss factor $(\tan \delta)$ of the sintered specimen indicates that the material is suitable for microwave applications.

\section{References}

Blasse G and Corsmit A F 1973 J. Solid State Chem. 6513
Corsmit A F, Hoefdraad H F and Blasse G 1972 J. Inorg. Nucl. Chem. 343401

Glieter H 2000 Acta Mater. $\mathbf{4 8} 1$

Goodenough J B 1971 Prog. Solid State Chem. 5145

Greenway D L and Harbeke G 1969 Optical properties and band structures of semiconductors (New York: Pergamon)

Karagedov G R and Lyakhov N Z 1999 Nanostruct. Mater. 11559

Kimura T and Tokura Y 2000 Ann. Rev. Mater. Sci. 30451

Kumar V R, Prasad V S, Wariar P R S and Koshy J 2011 NANO: Brief Reports and Reviews $\mathbf{6} 279$

Lavat A E, Grasselli M C, Baran E J and Mercader R C 2001 Mater. Lett. 47194

Lichtenburg F, Herrnberger A, Weidenmann K and Mannhart J 2001 Prog. Solid State Chem. 291

Nakamoto K 1986 Infrared and Raman spectra of inorganic and coordination compounds (New York: Wiley) 4th ed.

Nyguist R N and Kagel R O 1971 Infrared spectra of inorganic compounds (New York: Academic Press)

Osterloh F E 2008 Chem. Mater. 2035

Ratheesh R, Sreemoolanadhan H and Sebastian M T 1997 J. Solid State Chem. 1312

Ravichandran D, Roy R, Ravindranathan P and White W 2004 J. Am. Ceram. Soc. 821082

Sharma T P, Sharma S K and Singh V 1992 CSIO Commun. 1963

Skandan G, Chen Y J, Glumac N and Kear B H 1999 Nanostruct. Mater. 11149

Suryanarayana C 1994 Bull. Mater. Sci. 17307

Tauc J (ed.) 1974 Amorphous and liquid semiconductors (New York: Plenum) p. 159

Tovar H, Ortiz Díaz O, Landínez Téllez D A and Roa-Rojas J 2007 Phys. Status Solidi (c) 44294

Zheng W, Pang W and Meng G 1998 Mater. Lett. 37276 